\title{
DAMPAK INTEGRASI E-SERVICE QUALITY DAN E-SATISFACTION PADA E-REPURCHASE INTENSION KONSUMEN APLIKASI GO-JEK KATEGORI GO-RIDE
}

\author{
Sri Murni Setyawati \\ Jurusan Manajemen, Fakultas Ekonomi dan Bisnis, Universitas Jenderal Soedirman, Jl. HR. Boenyamin No. 708, \\ Purwokerto 53122, Jawa Tengah, Indonesia \\ *Email corresponding author: nunk_pwt@yahoo.co.id
}

\begin{abstract}
Abstrak
Penelitian ini akan menguji dampak integrasi kualitas pelayanan elektronik dan e-satisfaction pada erepurchase intention. Pemodelan struktural digunakan sebagai alat analisis. Penelitian ini menggunakan sampel sebanyak 114 pengguna layanan go-ride di wilayah Purwokerto. Hasil temuan penelitian menyatakan bahwa kualitas layanan elektronik mempunyai dampak positif pada kepuasan dan niat beli elektronik. Studi ini juga mendukung pandangan yang menunjukkan e-satisfaction mempuyai pengaruh positif pada e-repurchase intention. Serta, e-satisfaction sebagai variabel perantara hubungan kualitas pelayanan dan niat beli elektronik.
\end{abstract}

Kata Kunci: kualitas layanan, kepuasan dan niat beli elektronik.

\begin{abstract}
This study will analyze the effect of integration e-service quality and satisfaction on e-repurchase intentions. Structural modeling is used as an analytical tool. This study used 114 go-ride users in Purwokerto area. The results of the research findings: the quality services of electronic will raise the impact on e-satisfaction and purchase intention. This study supports that e-satisfaction also raise the effect on e-repurchase intention. Besides that, this study concludes that e-satisfaction as an intermediary variable in relation to service quality and electronic purchase intention.
\end{abstract}

Keywords: e-service quality, e-satisfaction, e-repurchase intention

\section{PENDAHULUAN}

Salah satu wujud dari perkembangan teknologi adalah penggunaan fasilitasi internet dalam berbagai aspek, termasuk pada bidang transportasi. Jasa transportasi ini penting untuk melancarkan kegiatan sehari-hari, baik anak kecil, muda, dewasa dan tua. Segala jenis transportasi dituntut untuk dapat lebih cepat. Waktu menjadi suatu yang sangat mahal bagi masyarakat di jaman ini, sehingga setiap orang akan mempertimbangkan kualitas suatu layanan dengan waktu.

Saat ini, ada banyak variasi pilihan dari penyedia transportasi, sehingga pengguna pun dituntut semakin selektif dalam memilih layanan. Mereka tidak sekedar membeli layanan jasa tetapi juga mempertimbangkan layanan yang melekat dalam produk jasa tersebut. Hal inilah yang membuat semakin meningkatnya persaingan di berbagai bisnis, termasuk transportasi. Perusahaan yang mampu bersaing inilah yang dapat tetap ada di era globalisasi. Cara untuk dapat bertahan dengan memberikan rasa puas pada konsumen. Lin dan Sun (2009) mengidentifikasikan beberapa faktor yang dapat memberikan rasa puas pada konsumen, menurut mereka, dengan meningkatkan kualitas layanan. Ketika kualitas layanan dikaitkan dengan layanan elektronik, maka dikenal kata e-service quality. Strategi perusahaan untuk dapat mencapai kepuasan konsumen adalah dengan meninggikan E-service quality.

Kualitas pelayanan elektronik dapat dilihat dari dua pandangan, yaitu dari pihak pelanggan dan perusahaan (Li et al, 2009). Jika dilihat dari pihak pelanggan, maka dimensinya adalah efficiency, fulfillment, privacy, responsiveness, contact dan website design. Sedangkan dari pihak perusahaan adalah kemudahan menggunakan, desain website, reliabilitas, ketersediaan system, privasi, daya tanggap dan empati. Penelitian ini menggunakan perspektif pelanggan karena ditujukan untuk mengukur tingkat kepuasan mereka dalam menggunakan layanan jasa. Kualitas layanan elektronik yang diberikan oleh perusahaan dapat menentukan rasa puas pada pelanggan. Kualitas layanan elektronik yang tinggi akan berdampak pada kepuasan pelanggan yang semakin meningkat. 
Penelitian Ario, et al (2016) juga menunjukkan bahwa semakin meningkatnya e-service quality maka rasa puas pelanggan semakin tinggi. E-service quality dan e-satisfaction adalah pendorong munculnya e-repurchase intention. Kotler (2014) menyatakan kepuasan pelanggan adalah rasa bahagia atau penyesalan yang timbul setelah konsumen mempertimbangkan apa yang dipikirkan dengan apa yang diterima. Seiring berkembanganya e-commerce, konsep kepuasan pelanggan dalam lingkup online menjadi e-satisfaction. E-satisfasction adalah gabungan dari kepuasan yang didapat oleh konsumen setiap kali mereka mengonsumsi barang atau jasa dalam sebuah situs online. Rasa puas konsumen akan mendorongnya untuk membeli ulang dan memberitakan kepada orang lain. Khalifa dan Liu (2007) juga menyatakan bahwa begitu konsumen merasakan puas maka e-repurchase intention konsumen terhadap produk/jasa akan meningkat. Berbeda dengan pernyataan Cronin \& Taylor (1992) yang membuktikan bahwa walaupun suatu perusahaan memberikan kualitas layanan yang baik, bukan jaminan konsumen akan melakukan pembelian ulang. Menurutnya, konsumen harus diarahkan pada perasaan puas jika ingin membuatnya kembali membeli layanan produk/jasa perusahaan.

Peneliti akan meneliti integrasi kualitas pelayanan elektronik dan e-satisfaction pada e-repurchase intention. Penelitian ini menggunakan objek para konsumen layanan go-jek khususnya go-ride di wilayah Purwokerto. Go-ride dipilih karena saat ini di kota Purwokerto, sangat padat kendaraan pribadinya terutama pada jam kerja. Sehingga, masyarakat lebih senang memakai transportasi ojek sepeda motor (go-ride) agar tidak mengalami kemacetan. Go-jek adalah perusahaan jasa transportasi pertama yang menyediakan jasa online untuk membantu menyejahterahkan masyarakat. Saat ini, Gojek mempunyai lebih dari dua ratus ribu pengendara ojek, baik di dalam maupun luar negeri. Adanya perkembangan teknologi internet telah memudahkan masyarakat untuk dapat memesan transportasi. Maka, go-jek memerlukan strategi bisnis untuk dapat mencapai keunggulan kompetitif dibanding pesaingnya yang sama-sama bergerak di bidang transportasi online. Peneliti ingin mengintegrasi hubungan kualitas layanan elektronik dan e-satisfaction pada e-repurchase intention, pengguna layanan go-jek kategori go-ride wilayah Purwokerto.

\section{TINJAUAN PUSTAKA DAN PERUMUSAN HIPOTESIS \\ E-service quality}

Didefinisikan sebagai penilaian pelanggan secara umum mengenai keunggulan dan kualitas dari pelayanan yang disampaikan oleh perusahaan (Wijiutami, 2017). Variabel ini memiliki 6 dimensi (AlHawari,2014) sebagai berikut:

Efficiency; yaitu kecakapan pelanggan dalam menggunakan website untuk memperoleh barang atau jasa serta informasi yang ada di dalamnya.

Fulfillment; yaitu terdiri dari akurasi dalam kesepakatan pelayanan, penyediaan jumlah barang atau jasa, dan pengiriman barang atau jasa sesuai dengan waktu yang telah disepakati.

Privacy; yaitu pertanggungan bahwa informasi pelanggan tak akan disampaikan pada pihak manapun, termasuk data kartu kredit.

Responsiveness; yaitu kemampuan perusahaan untuk menyampaikan informasi yang tepat serta terpercaya kepada konsumen, terutama saat mereka menghadapi masalah terkait produk/jasa.

Contact; yaitu cerminan bahwa pelanggan dapat berkomunikasi secara langsung dengan pihak perusahaan bukan melalui aplikasi mesin otomatis.

Website design; yaitu sejauh mana situs web memberikan fasilitas yang efisien dan efektif kepada pelanggannya.

\section{E-satisfaction}

Didefinisikan sebagai pengalaman konsumen dalam menggunakan internet dibanding ketika mereka menggunakan cara yang tradisional (Amin,2016). E-satisfasction adalah gabungan dari kepuasan yang didapat oleh konsumen setiap kali mereka mengonsumsi barang atau jasa dalam sebuah situs online . Islam et al., dalam Hansen dan Jonsson (2013) mengemukakan bahwa e-satisfaction adalah bentuk evaluasi setelah konsumen mengonsumsi suatu produk atau jasa. Pada penelitian ini, ada lima indikator yang digunakan yaitu: (Bulut, 2015): Senang dengan layanan yang diterima, merasa puas dengan layanan, bahagia saat melakukan transaksi pembelian dengan website. merasa puas dengan keputusan pembelian yang telah dilakukan secara online, merasa bahwa keputusan pembelian yang telah dilakukan adalah keputusan bijak. 


\section{E-repurchase intention}

Cronin, 2000 mendefinisikannya sebagai respon positif pelanggan pada kualitas pelayanan elektronik perusahaan dan berniat untuk mengunjungi kembali serta mengonsumsi produk/jasa perusahaan tersebut. Penelitian ini menggunakan empat indikator yaitu : Konsumen ingin datang kembali, menjadi prioritas utama dalam pembelian, memberikan saran pada orang lain yang ingin membeli produk, memberitahukan informasi positif kepada banyak orang.

\section{Hubungan kualitas layanan dan niat beli elektronik}

Dolatabadi et al (2012) dalam penelitiannya menyatakan jika e-service quality secara kuat mempengaruhi keinginan untuk membeli ulang. Pernyataan ini didukung oleh Bao, Jinlong (2015), ia membuktikan bahwa dalam niat beli ulang secara signifikan dipengaruhi oleh kualitas layanan produk. Gupta \& Kim (2007) menyatakan bahwa untuk menemukan konsumen baru akan lebih merugikan perusahaan daripada menjaga konsumen yang telah ada. Salah satu cara untuk tetap mengikat pelanggan pada perusahaan adalah meningkatkan kualitas pelayanannya. Maka dapat dirumuskan:

$H_{1}$ : Kualitas layanan dapat meningkatkan niat beli elektronik.

\section{Hubungan kualitas pelayanan dan kepuasan elektronik}

Pemberian kualitas layanan elektronik kepada konsumen akan mendorongnya untuk merasa puas/tidak puas . Faktor yang paling dominan untuk memberi rasa puas pada pelanggan adalah kualitas layanan. Di bidang jasa, kualitas layanan elektronik akan sangat dioertimbangkan oleh pengguna layanan, mereka akan puas jika kualitas pelayanan yang diberikan semakin baik. Hasil penelitian Santika, I Wayan dan Komang (2018), Ario et al (2016), Sawitri et al (2013), Ristina (2013), dan Felicia (2016) juga mendukung pernyataan ini. Maka dapat dirumuskan:

$\mathrm{H}_{2}$ : E-service quality dapat meningkatkan e-satisfaction.

\section{Hubungan e-satisfaction dan e-repurchase intention}

Dian dan Rusfian (2013), dalam penelitiannya menyatakan kepuasan yang didapat konsumen memiliki pengaruh positif dengan pembelian ulang. Konsumen yang menyatakan dirinya puas terhadap suatu produk akan cenderung untuk mengulangi pembeliaannya. Penelitian ini juga didukung oleh Ha, Janda dan Muthaly (2010). Mereka beranggapan bahwa konsumen memiliki niat beli ulang karena ingin terhindar dari resiko ketidakpuasan dari perusahaan lain. Weisberg, Te'eni, dan Arman (2011) juga menyatakan bawa pelanggan berniat melakukan pembelian ulang karena mereka memiliki tingkat kepercayaan yang tinggi pada perusahaan tersebut.. Maka dapat dirumuskan:

$H_{3}$ : Terdapat hubungan positif antara e-satisfaction dengan e-repurchase intention.

\section{Hubungan e-satisfaction, e-service quality dan e-repurchase intension}

Khalifa dan Liu (2007) menyatakan bahwa begitu konsumen merasakan puas karena kualitas layanan yang perusahaan berikan maka e-repurchase intention konsumen terhadap produk/jasa akan meningkat. Penelitian Gounaris et al(2010) menunjukkan bajwa e-service quality memiliki pengaruh yang kuat dengan niat beli sebagai bentuk umpan balik dari pelanggan. Maka dapat dirumuskan:

$H_{4}$ : E-satisfaction sebagai perantara hubungan e-service quality dan e-repurchase intension. 


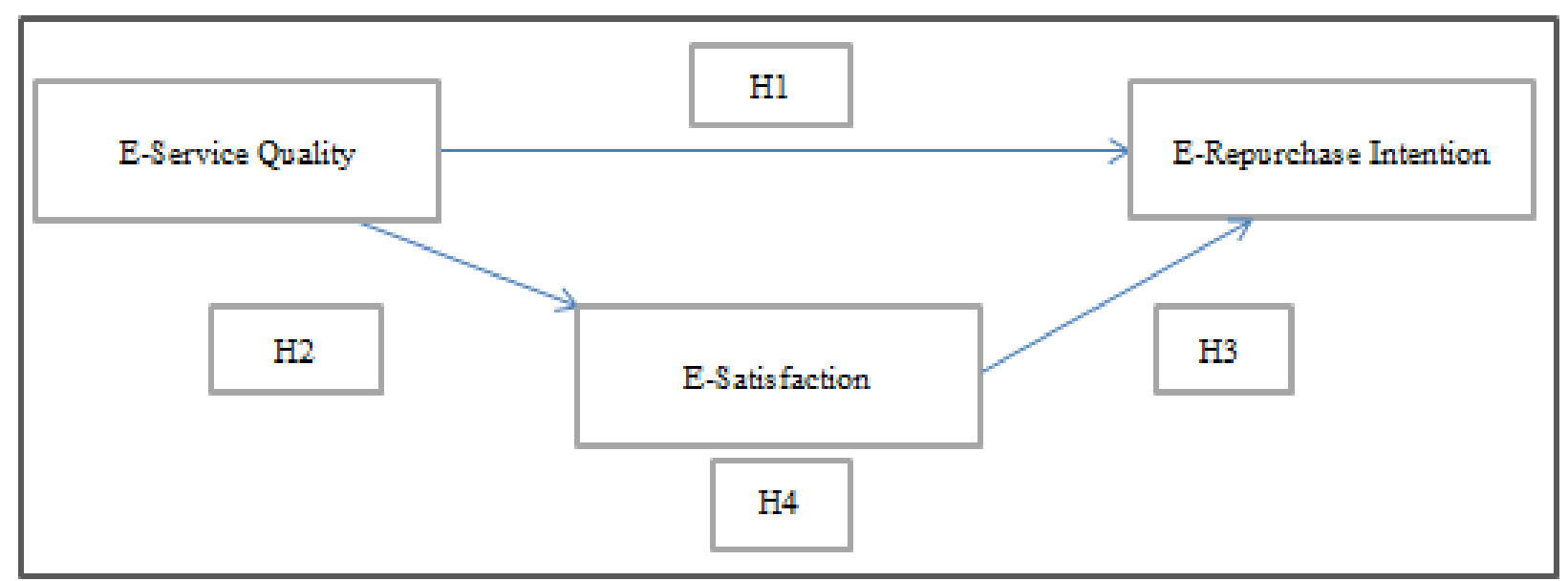

\section{METODE PENELITIAN}

Seluruh pemakai layanan go-ride di wilayah Purwokerto dijadikan populasi pada penelitian. Metode dalam mengumpulkan data adalah dengan mendistribusikan kuesioner berskala 1-7 dan wawancara secara langsung. Menurut Hair, et al (2010), sampel minimumnya yaitu 100 responden. Penelitian ini menggunakan sampel 108 (18x6). Karena setiap pemakai layanan go-ride memiliki kesempatan yang sama untuk dijadikan sampel, maka metode pengambilan sampel secara acak digunakan dalam penelitian ini. Adapun jumlah sampel yang diambil dariStructural Equation Modelling (SEM) digunakan untuk menguji model empiris. Alat analisis lain yaitu SPSS 16.0, AMOS 21.0, Excel 2010.

\section{HASIL DAN PEMBAHASAN}

Hasil uji menunjukkan bahwa semua indikator yang digunakan reliabel dan memiliki validitas yang baik sehingga dapat digunakan pada tahap berikutnya. Hair,et al (2010) menyatkan uji kesesuaian model ini dapat dikategorikan fit jika minimal 5 kriteria terpenuhi. Hasil pengujian kita lihat pada tabel 1.

Tahel 1. Hasil Uji Kesesuaian Model (Goodness of Fit Test)

\begin{tabular}{llll}
\hline \multicolumn{1}{c}{ Indeks Kesesuaian Model } & Cut-off Value & Hasil Analisis Model & Keterangan \\
\hline$x^{2}-$ Chi Square & $\left(\chi^{2} 98,08147\right.$ & 79,594 & Baik \\
& $(p 0,05 ; \mathrm{df} 74)$ & & \\
Probability & $\geq 0,05$ & 0,307 & Baik \\
CMIN/DF & $\leq 2,00$ & 1,076 & Baik \\
RMSEA & $\leq 0,08$ & 0,028 & Baik \\
GFI & $\geq 0,90$ & 0,899 & Marginal \\
AGFI & $\geq 0,90$ & 0,857 & Marginal \\
TLI & $\geq 0,95$ & 0,988 & Baik \\
CFI & $\geq 0,95$ & 0,990 & Baik \\
\hline
\end{tabular}




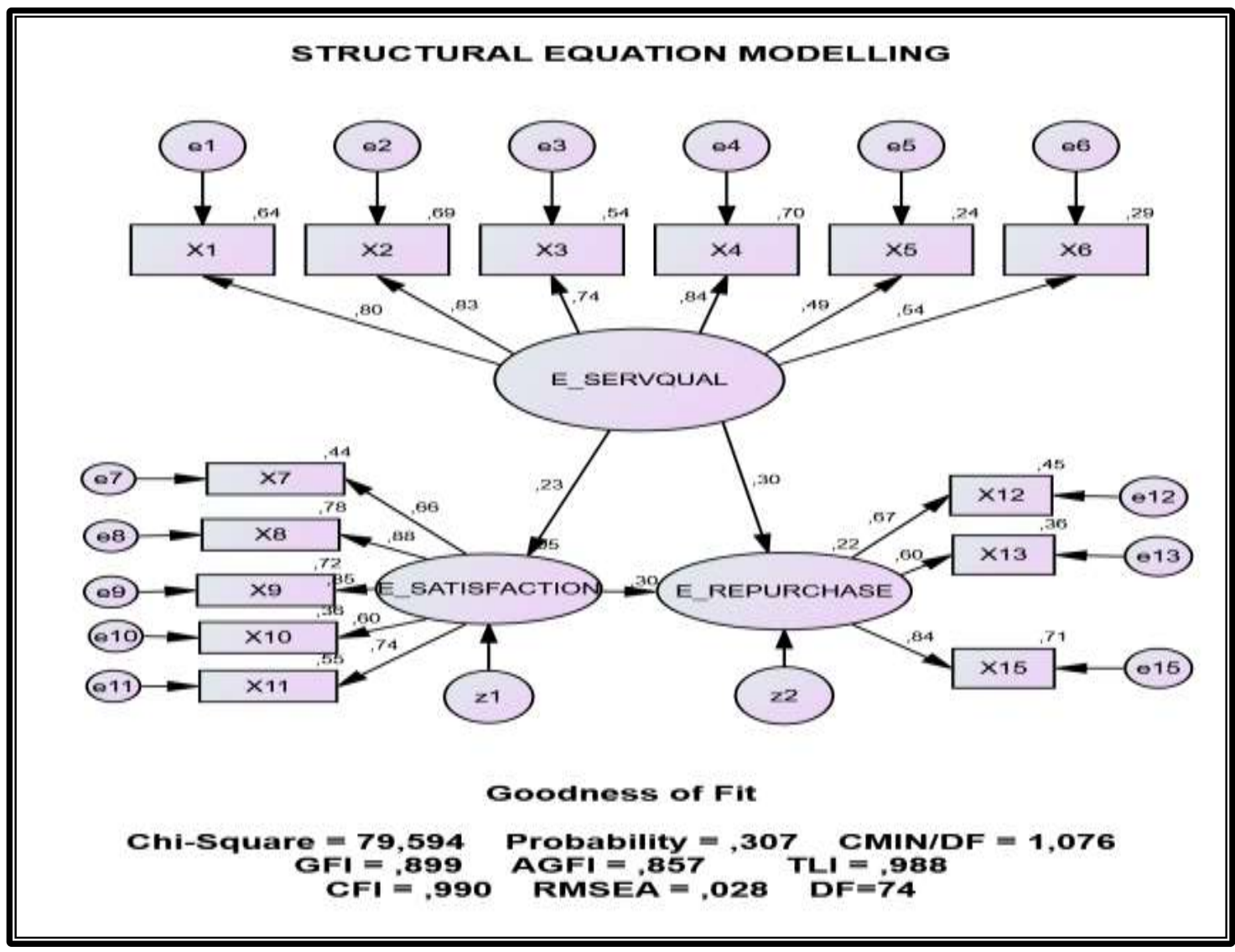

Gambar 1. Full Model Persamaan Struktural

\section{Pengujian Hipotesis}

Tabel 2. Uji Hipotesis Penelitian

\begin{tabular}{lcccc}
\hline \hline Hipotesis & Nilai CR. & $\begin{array}{c}\text { Nilai } \\
\mathbf{t}_{\text {tauk }}\end{array}$ & $\mathbf{P}$ & Hasil Uji \\
\hline E-Servqual $\rightarrow$ E-Satisfaction & 2,019 & 1,981 & 0,043 & Diterima \\
E-Servqual $\rightarrow$ E-Repurchase Intention & 2,336 & 1,981 & 0,019 & Diterima \\
E-Satisfaction $\rightarrow$ E-Repurchase Intention & 2,292 & 1,981 & 0,022 & Diterima \\
\hline \hline
\end{tabular}

Sumber: Data Primer

Uji mediasi e-satisfaction sebagai perantara e-service quality dan e-repurchase intention

Berdasarkan perhitungan rumus Sobel, nilai Z table $(1,96)$ lebih kecil dari Z hitung $(5,69)$. Maka, dapat ditarik kesimpulan bahwa e-satisfaction sebagai perantara hubungan antara kualitas layanan dan niat beli elektronik.

\section{Pembahasan Hipotesis}

Kualitas layanan dan niat beli elektronik

Hipotesis yang menyatakan bahwa e-service quality memberikan pengaruh positif pada e-repurchase intention, diterima. Maka semakin tinggi perusahaan memberikan kualitas layanan, niat beli ulang yang dilakukan konsumen semakin besar pula. Jika dilihat dari kondisi layanan go-ride, perusahaan telah berusaha untuk memberikan layanan terbaiknya bagi pelanggan. Seperti, kemudahan pelanggan dalam menggunakan aplikasi go-ride, ketepatan estimasi waktu, pemilihan rute yang cepat, kebersihan, pengendara ojek yang cepat dalam merespon tanggapan pengguna layanan, pencantuman nama, nomer handphone dan plat pengendara go-jek yang membuat pengguna merasakan nyaman saat menggunakan layanan go-ride, dll. Beberapa hal inilah yang mendorong pengguna untuk menggunakan kembali aplikasi go-ride. mereka tidak ingin beralih ke produk lain. Kualitas layanan yang seperti inilah 
yang membuat konsumen go-jek terdorong untuk melakukan pembelian ulang. Niat beli elektronik yang diraih oleh perusahaan akan dapat menjadi modal keunggulan kompetitidf dibanding pesaing. Karena perusahaan akan dapat menghemat biaya jika dibanding harus mencari pelanggan baru. Hasil ini didukung oleh Bao, Jinlong (2015). Sari, Dita (2016).

\section{Kualitas layanan dan kepuasan elektronik}

Hipotesis yang menyatakan bahwa kualitas layanan elektronik memberikan dampak positif pada esatisfaction, diterima. Maka semakin tinggi perusahaan memberikan kualitas layanan maka kepuasan yang didapat oleh konsumen pun semakin tinggi. Memberikan kepusan kepada pelanggan adalah hal yang menjadi tujuan para penyedia layanan jasa/produk. Pelanggan adalah asset terbesar bagi suatu usaha, baik dalam jangka waktu pendek ataupun panjang. Perusahaan tidak akan bisa bertahan apabila tidak mempunyai pelanggan. Dan memang sudah menjadi kewajiban bagi perusahaan jasa transportasi online untuk lebih memperhatikan kualitas layanannya dibanding hanya sekedar memasarkan produknya ke konsumen. Kemampuan perusahaan dalam melayani konsumen akan menjadi senjata yang ampuh untuk dapat menciptakan kepuasan dan memenangkan persaingan. Banyak penelitian yang telah berhasil membuktikan pengaruh kualitas layanan dan kepuasan elektronik. Apabila kualitas pelayanan yang diberikan baik maka akan tercipta kepuasan, namun bila perusahaan tidak memberikan kualitas layanan terbaiknya, pelanggan akan merasa kecewa dan beralih pada produk lain. Penelitian ini didukung oleh hasil penelitian Bahar (2013), Melinda (2017), Steven dan Kunto (2014), Ting et al (2016), Ghalandari, Kamal (2012).

\section{Kepuasan dan niat beli elektronik}

Hipotesis yang menyatakan e-satisfaction memberikan dampak positif pada niat beli ulang elektronik, diterima. Apabila kepuasan yang didapat konsumen semakin tinggi, maka ia akan terdorong untuk melakukan pembelian ulang. Dalam penggunaan aplikasi go-ride, konsumen selalu diminta untuk memberikan penilaian kepada driver. Semakin tinggi bintang yang ia berikan, menunjukkan semakin ia puas dalam penggunaan layanan. Saat ini, kepuasan pelanggan harus dicapai oleh semua perusahaan karena hal inilah yang menentukan keberhasilan suatu usaha. Apabila konsumen kecewa, mereka akan beralih dari layanan yang kita tawarkan. Dan hal ini akan membuat perusahaan mengalami kerugian karena kehilangan pelanggan. Penelitian ini mendukung pernyataan Sumarwan (2014), yang menyatakan kepuasan pelanggan akan mendorong terciptanya proses pembelian ulang. Karena mereka berharap bahwa apabila mereka menggunakan layanan jasa ini, mereka akan mendapat kepuasan yang sama seperti saat mereka mencoba pertama kali. Mereka merasa enggan untuk mencoba produk lain yang belum tentu akan lebih memuaskan mereka. Sehingga sekali konsumen merasa puas, ia akan mempunyai niat beli ulang. Hasil penelitian Ha, Janda dan Muthaly (2010) juga mendukung penelitian ini.

\section{E-satisfaction, e-service quality, dan e-repurchase intention}

Diterimanya hipotesis ini menandakan bahwa e-satisfaction dapat dijadikan sebagai perantara hubungan e-service quality dan e-repurchase intension. Dengan kata lain, ini merupakan sebuah model keberlanjutan. Apabila perusahaan ingin mendorong terciptanya niat beli ulang para pelanggannya, perusahaan harus memberikan rasa puas kepada mereka. Rasa puas itu akan didapat apabila mereka mendapatkan sesuatu yang lebih dari apa yang diharapkan, sebagai contoh mereka merasa puas karena layanan yang diberikan oleh driver go-ride. Ketika mereka merasa puas, mereka akan berniat membeli ulang produk yang diberikan oleh perusahaan. Hasil penelitian yang mendukung adalah pernyataan Khalifa dan Liu (2007). Mereka menyatakan bahwa begitu konsumen merasakan puas karena kualitas layanan yang perusahaan berikan maka e-repurchase intention konsumen terhadap produk/jasa akan meningkat. Hasil penelitian Gounaris et al(2010) menyatakan setelah pelanggan mendapat kualitas layanan yang terbaik dari perusahaan, ia akan merasa puas dan memengaruhi niatnya untuk membeli ulang.

\section{KESIMPULAN}

Dapat disimpulkan bahwa kualitas layanan elektronik mampu meningkatkan e-satisfaction dan erepurchase intention. Studi ini juga mendukung pandangan bahwa e-satisfaction memiliki pengaruh pada niat beli elektronik. Serta, e-satisfaction sebagai variabel perantara hubungan e-service quality dan e-repurchase intention. Implikasi dari penelitian yaitu: 
1. Dalam kaitannya dengan informasi yang ada dalam variabel e-service quality, pihak manajemen gojek khususnya dalam go-ride diharapkan dapat memperbaiki estimasi waktu tunggu yang ada pada aplikasi. Sehingga pengguna aplikasi dapat semakin nyaman dalam menggunakannya.

2. Pihak manajemen go-jek khususnya go-ride harus selalu meningkatkan pelayanan sehingga dapat memberikan kepuasan pelanggan.

3. Pihak manajemen go-jek khususnya go-ride diharapkan untuk dapat menambah kegiatan promosi sehingga dapat meningkatkan brand awareness layanan go-jek.

4. Pihak go-ride dapat menganalisis beberapa faktor lain seperti harga dan metode pembayaran yang dapat mempengaruhi kualitas pelayanan. Sehingga dapat lebih meningkatkan kepuasan pelanggan dan dapat membuatnya melakukan pembelian ulang.

5. Pihak manajemen go-jek khususnya go-ride seharusnya mengarahkan mitranya untuk melayani pelanggan dengan maksimal.

6. Pihak manajemen go-jek khususnya go-ride diharapkan dapat menindaklanjuti lembar saran yang telah diisi oleh pelanggan. Hal ini ditujukan agar perusahaan pelanggan dapat mengetahui timgkat kepuasan konsumen dan menjalin hubungan komunikasi yang baik dengan pelanggan.

Ada beberapa hal yang menjadi kekurangan peneliti seperti hanya fokus pada sektor go-jek. Untuk penelitian selanjutnya sebaiknya fokus pada beberapa sektor untuk perbandingan. Penelitian mendatang juga diharapkan untuk membuat kuesioner terbuka sehingga hasil yang didapat lebih objektif.

\section{DAFTAR PUSTAKA}

Al-Hawari, Mohammad A. 2014. Does Customer Sociability Matter? Differences ini E-Quality, ESatisfaction, and E-Loyalty Between Introvert and Extrovert Online Banking Users. Journal of Service Marketeing. Vol. 28, issue 07, pp. 538-546.

Amin, Muslim. 2016. Internet Banking Service Quality and It's Implication on E-Customer Satisfaction and E-Customer Loyalty. International Journal of Bank Marketing, Vol. 34, Issue 03, pp. 280-306.

Ario, A.A., Djatmiko, T. 2016. Pengaruh E-Service Quality terhadap E-Customer Satisfaction dan ECustomer Loyaly pada Lazada.co.id. e-proceeding. Universitas Telkom, Fakultas Ekonomi dan Bisnis, Prodi Manajemen Bisnis Telekomunikasi dan Informatika.

Bahar, Taslim., Tamin, Ofyan., Kusbiantoro, B.S., Frazila, Russ Bona. 2009. Pengaruh Kualitas Pelayanan Terhadap Kepuasan Dan Loyalitas Penggunaan Moda Angkutan Umum Informal (Studi Kasus Ojek Sepeda Motor). Jurnal Simposium XII FSTPT, Hal. 972-981.

Bao, Jinlong. 2015. The Impacts of E-Service Quality on Customer's Repurchase Intention in Platform Online Retailing: An Empirical Investigation. Wuhan International Conference on e-Business.

Bulut,Z.A. 2015. Determinants of Repurchase Intention in Online Shopping: A Turkish Consumer's Perspective. International Journal of Business and Social Science. Vol.06, No.10.

Cronin, J.J., brady, M.K and Hult, G.T.M. 2000. Assesing the Effects of Auality, Value and Customer Satisfaction on Consumer Behavioral Intentions in Service Environments. Journal of Retailing. Vol. 76, No.02.

Cronin, J.J., dan Taylor S.A. 1992. Measuring Service Quality: A Reexamination and Extension. Journal of Marketing. Vol. 56.

Dian, Ristian dan Rusfian Effy Z. 2013. Pengaruh E-Service Quality terhadap Repurchase Intention melalui Customer Satisfaction (Studi pada Online Shop Gasoo Galore). Jurnal Ilmu Administrasi Niaga Universitas Indonesia.

Dolatabadi, Hossein Rezaei dan Mashid Gharibpoor. 2012. How Can E-Service Influence on Customers Intentions toward Online Booj Repurchasing. International Journal of Academic Research in Business and Social Sciences. Vol. 02, No. 06.

Felicia, L. 2016. Pengaruh E-Service Quality terhadap Loyalitas Pelanggan Go-jek melalui Kepuasan Pelanggan. Jurnal AGORA. Vol.04, No.02.

Ghalandri, Kamal. 2012. The Effect of E- Service Quality on E- Trust and E-Satisfaction as Key Factors Influencing Creation of E-Loyalty in E-Business Context: The Moderating Role of Situational Factors. Journal of Basic and Applied Scientific Research. . Vol. 02, No. 12. 
Gounaris, Spiros, Sergios Dimitriadis, Vlasis Stathakopoulos. 2010. An Examination of the Effect of Service Quality and Satisfaction on Customer's Behavioral Intention in E-Shopping. Journal of Service Marketing. Vol. 24, No.02.

Gupta, Sumeet dan Hee Woong Kim. 2007. Developing the Commitment to Virtual Community: The Balanced Effects of Cognition and Affect. Information Resources Management Journal. Vol. 20, No. 01 , pp. 28-45.

Hair, Joseph F., et al. 2010. Multivariate Data Analysis. Pearson Prentice Hall.

Hansen, E., \& Jonsson, E. 2013. E-Loyalty in Fashion e-Commerce: An Investigation in How to Create ELoyalty. Master Thesis. Linnaeus University.

Hong-Youl Ha, Swinder Janda, Siva K. Muthaly. 2010. A New Understanding of Satisfaction Model in Ere-purchase Situation. European Journal of Marketing. Vol. 44, Issue:7/8, pp. 997-1016, https://doi.org/10.1108/03090561011047490.

Jacob Weisberg, Dov Te'eni, Limor Arman. 2011. Past purchase and intention to purchase in ecommerce: The mediation of social presence and trust. Internet Research, Vol. 21 Issue: 1, pp.8296, https://doi.org/10.1108/10662241111104893.

Khalifa, Mohamed dan Vanessa Liu. 2007. Online Customer Retention: Contingent Effects of Online Shopping Habit and Online Shopping Experiences. Paper. University of Wollongong, Australia.

Kotler dan Keller. 2012. Manajemen Pemasaran. Ed. 12, Jakarta: Erlangga.

Lin, G.T.R dan Sun, C.C. 2009. Factors Influencing Satisfaction and Loyalty in Online Shopping: An Ontegrated Model. Online Information Review.

Melinda. 2017. Pengaruh E-Service Quality terhadap E- Loyalty Pelanggan Go-jek melalui E-Satisfaction pada Kategori Go-Ride. Jurnal Agora. Vol. 05, No.01.

Ristina, D.A. dan Rusfian, E. 2013. Pengaruh E-Service Quality terhadap Repurchase Intention melalui Customer Satisfaction. Naskah Ringkas. Universitas Indonesia, Program Studi Ilmu Administrasi Niaga.

Santika, I Wayan, dan Komang Agus Satria Pramudana. 2018. Peran Mediasi E-Satisfaction pada Pengaruh E-Service Quality terhadap E-Loyalty Situs Online Travel di Bali. INOBIS: Jurnal Inovasi Bisnis dan Manajemen Indonesia. Vol. 01, No. 03, Juni.

Sari, DIta Puspita. 2016. Pengaruh Iklan, Harga, dan E-Service Quality terhadap Repurchase Intention pada Pengguna Online Travel Agent Traveloka. Skripsi. Universitas Islam Negeri Syarif Hidayatullah Jakarta.

Sawitri, N.P., Kerta Yasa, N,N., Jawas, A. 2013. Pengaruh Kualitas Pelayanan terhadap Kepuasan dan Loyalitas Pelanggan Tegalsari Acc di Ubud. Jurnal Matrik. Vol. 07, No.01.

Ting, Ong S., Ariff, Mohd. S., Zakuan, N. Sualaiman , Z dan Saman. 2016. E-Service Quality, E-Satisfaction, and E-Loyalty of Online Shoppers in Business to Consumer Market; Evidence from Malaysia. IOP Conf. Series: Materials Science and Engineering, doi: 10.1088/1757-899X/131/1/012012.

Wijiutami, Shinta Sekaring dan Damayanti Octavia. 2017. Pengaruh E-Service Quality terhadap ESatisfaction serta Dampaknya pada E-Loyalty Pelanggan E-Commerce C2C di Kota Jakarta dan Bandung. E-proceeding of Management. Vol. 04, No.03. 